\title{
Performance Evaluation of Hata-Davidson Pathloss Model Tuning Approaches for a Suburban Area
}

\author{
Wali Samuel $^{1}$, Njumoke N. Odu ${ }^{2}$, Samuel Godwin Ajumo ${ }^{2}$ \\ ${ }^{1}$ Department of Electrical/Electronic and Computer Engineering, University of Uyo, Uyo, Nigeria \\ ${ }^{2}$ Department of Electrical/Computer Engineering, Port Harcourt Polytechnic, Port Harcourt, Nigeria
}

Email address:

samwalliuy@yahoo.com (W. Samuel)

To cite this article:

Wali Samuel, Njumoke N. Odu, Samuel Godwin Ajumo. Performance Evaluation of Hata-Davidson Pathloss Model Tuning Approaches for a Suburban Area. American Journal of Software Engineering and Applications. Vol. 6, No. 3, 2017, pp. 93-98. doi: 10.11648/j.ajsea.20170603.16

Received: January 3, 2017; Accepted: January 18, 2017; Published: June 23, 2017

\begin{abstract}
In this paper, comparative study of RMSE-base tuning and multi-parameter-based tuning of Hata-Davidson pathloss model for a suburban area is presented. The study was based on field measurement of received signal strength carried out in a suburban area for a GSM (Global System for Mobile communication) network that operates in the $1800 \mathrm{MHz}$ frequency band. The results show that multi-parameter-tuned Hata-Davidson model has better prediction accuracy of $98.70720432 \%$ and RMSE of $2.177522885 \mathrm{~dB}$ as against the RMSE-tuned Hata-Davidson model with prediction accuracy of $97.42722692 \%$ and RMSE of 4.256897001dB. However, the RMSE is quite simple and easier to implement even in embedded systems and systems with limited resource.
\end{abstract}

Keywords: Pathloss, Propagation Model, Hata-Davidson Model, Model Optimisation, Multi-Parameter-Based Tuning Method, RMSE-Base Tuning Method, Least Square Error Method

\section{Introduction}

Pathloss models are essential in planning wireless network. The models provide mathematical expressions that enable network designers to determine the amount of pathloss that will be experienced by the signal as it transverse the given terrain [1-5]. Basically, a propagation pathloss model predicts the difference between the transmitted power and the receiver power using empirical and deterministic methods or a combination of both. Empirical models, in general, require adjusting some parameters according to field measurements made in a particular environment. Several empirical pathloss models have been given attention for decades due to their accuracy and environmental compatibility. However, peculiarities of these models give rise to high prediction errors when deployed in a different environment other than the one they are initially built for. For instance, [6] provides the error bounds on the efficacy at predicting pathloss for eight widely used empirical pathloss models based on field strength measurements conducted in the VHF and UHF frequencies in Kwara State, Nigeria. It was concluded that no single model would provide a good fit consistently. Faruk, Adediran and Ayeni, [7] presented similar results to that of [6] and concluded that tuning of pathloss model is necessary to minimize the RMSE value within the acceptable range. For example, Dalela, Prasad and Dalela, [9] presented tuning of COST 231 Hata model based on measurements conducted in $2.3 \mathrm{GHz}$ in Western India. Also. linear iterative method was used in tuning the model and it was found that the tuned model achieved better root mean square errors as compared with the conventional COST 231 Hata model. Isabona and Azi, [10] optimized Walficsh Bertoni model using least squares method. The optimized model predicts pathloss with improved accuracy of about 25-30\% compared to the original model. Chen and Hsieh [11] provided a fast and precise dual least-square approach to tune the generally used propagation models, like COST231-Hata model. In this paper, two different least square optimization techniques are used for optimizing the 
Hata-Davidson model [12]. The first approach is based on addition or subtraction of the RMSE value whereas the second approach is based on the adjustment of some Hata-Davidson model parameters in such a way as to minimise the sum of square error. The performance of the two tuning approaches are compared in terms of their RMSE and prediction accuracy.

\section{Method}

The field measurement route is identified with respect to the Cellular Network Base Station (CNBS) selected for the study. Received Signal Strength (RSS) and spatial data (longitude, latitude and altitude) dataset are then collected along the route. Samsung Galaxy S4 mobile phone with Cellmapper android application installed is used to capture and store the RSS and spatial datasets in CSV file. The RSS is converted to the measured pathloss (PL) using the formula [13-15]:

$$
d=2 r\left\{\sqrt[2]{\sin \left(\frac{L A T_{2}-L A T_{1}}{2}\right)^{2}+\cos \left(L A T_{1}\right) \cos \left(L A T_{2}\right) \sin \left(\frac{L O N G_{2}-L O N G_{1}}{2}\right)^{2}}\right\}
$$

$$
\text { LAT in Radians }=\frac{(\text { LAT in Degrees } * 3.142)}{180}
$$

LONG in Radians $=\frac{(\text { LONG in Degrees } * 3.142)}{180}$

Where

LAT1 and LAT2 are the latitude of the coordinates of point1 and point 2 respectively.

LONG1 and LONG2 are the longitude of the coordinates of point1 and point 2 respectively.

$\mathrm{R}=$ radius of the earth $=6371 \mathrm{~km} ; \mathrm{R}$ varies from $6356.752 \mathrm{~km}$ at the poles to $6378.137 \mathrm{~km}$ at the equator

$\mathrm{d}=$ the distance between the two coordinates

Eventually, the distance (d) data is used in the Hata-Davidson model to generate the predicted pathloss. The prediction accuracy of the pathloss model is evaluated with respect to the measured pathloss. The optimised pathloss model is then develop to improve on the prediction accuracy of the Hata-Davidson model. Finally, the prediction accuracy of the optimised pathloss model is compared with the prediction accuracy of the original (un-optimised) Hata-Davidson model.

$$
P L_{m(d B)}=\mathrm{P}_{\mathrm{BTS}}+\mathrm{G}_{\mathrm{BTS}}+\mathrm{G}_{\mathrm{MS}}-\mathrm{L}_{\mathrm{FC}}-\mathrm{L}_{\mathrm{AB}}-\mathrm{L}_{\mathrm{CF}}-\mathrm{RSS}(\mathrm{dBm})(1)
$$

where

for each measurement location at a distance $\mathrm{d}(\mathrm{km})$

RSS is the mean Received Signal Strength (RSS) in $\mathrm{dBm}$

$\mathrm{P}_{\mathrm{BTS}}=$ Transmitter Power $(\mathrm{dBm}), \mathrm{G}_{\mathrm{BTS}}=$ Transmitter Antenna Gain $(\mathrm{dBi}), \mathrm{G}_{\mathrm{MS}}=$ receiver antenna gain $(\mathrm{dBi}), \mathrm{L}_{\mathrm{FC}}=$ feeder cable and connector loss $(\mathrm{dB}), \mathrm{L}_{\mathrm{AB}}=$ Antenna Body Loss $(\mathrm{dB})$ and $\mathrm{L}_{\mathrm{CF}}=$ Combiner And Filter Loss $(\mathrm{dB})$. The values of these parameters are given as [13]: $\mathrm{P}_{\mathrm{BTS}}=40 \mathrm{~W}=46$ $\mathrm{dBm}, \mathrm{G}_{\mathrm{BTS}}=18.15 \mathrm{dBi}, \mathrm{G}_{\mathrm{MS}}=0 \mathrm{dBi}, \mathrm{L}_{\mathrm{FC}}=3 \mathrm{~dB}, \mathrm{~L}_{\mathrm{AB}}=3 \mathrm{~dB}$, $\mathrm{L}_{\mathrm{CF}}=4.7 \mathrm{~dB}$. Hence,

$$
P L_{m(d B)}=53.5(\mathrm{dBm}) .-\mathrm{RSS}(\mathrm{dBm})
$$

Again, the Haversine formula in Eq 3 is used to computer the distances (d) between each measurement point and the base station as follows;

\subsection{Hata-Davidson Propagation Model}

Hata-Davidson model is one of the extensions or modified versions of Hata model. Particularly, Hata-Davidson is Telecommunications Industry Association (TIA) recommended model following modification to the Hata model to cover a broader range of input parameters. The modification consists of the addition of correction terms to the Hata model.

The following equations are used for the computation of the pathloss (in $\mathrm{dB}$ ) according to the Hata-Davidson model [12]:

$$
L P_{\text {Hata_Davidson }}=L P_{\text {HATA }}+K_{\text {Davidson }}
$$

Where

is the pathloss prediction by the Hata model and is the correction factor introduced by Davidson. The following equations are used for the computation of pathloss (in $\mathrm{dB}$ ) according to the Hata model:

$L P_{O_{K_{-}} H_{A T A}(u r b a n)}=A+B * \log _{10}(d)$ for Urban

$$
\begin{gathered}
L P_{O_{-} H A T A(\text { suburban })}=A+B * \log _{10}(d)-C \text { for Suburban } \\
L P_{O_{-} H A T A(\text { open } / \text { rural })}=A+B * \log _{10}(d)-D \text { for Rural } \\
A=69.55+26.16 * \log _{10}(f)-13.82 * \log _{10}\left(h_{b}\right)-a\left(h_{m}\right) \\
B=44.9-6.55 * \log _{10}\left(h_{b}\right) \\
C=5.4+2 *\left[\log _{10}\left(\frac{f}{28}\right)\right]^{2} \\
D=40.94+4.78 *\left[\log _{10}(f)\right]^{2}-18.33 * \log _{10}(f) \\
a\left(h_{m}\right)=\left[1.1 * \log _{10}(f)-0.7\right] * h_{m}-\left[1.56 * \log _{10}(f)-0.8\right]
\end{gathered}
$$

Eq 8 is for small city, medium city, open area, rural area and suburban area. 
Now, for large city

$$
\begin{gathered}
a\left(h_{m}\right)=8.28 *\left[\log _{10}\left(1.54 * h_{m}\right)\right]^{2}-1.1 \mathrm{f} \leq 200 \mathrm{MHz} \\
a\left(h_{m}\right)=3.2 *\left[\log _{10}\left(11.75 * h_{m}\right)\right]^{2}-4.97 \mathrm{f} \geq 400 \mathrm{MHz}
\end{gathered}
$$

Where

- $\mathrm{f}$ is the centre frequency $\mathrm{f}$ in $\mathrm{MHz}$

- $\mathrm{d}$ is the link distance in $\mathrm{km}$

- is an antenna height-gain correction factor that depends upon the environment

- C and D are used to correct the small city formula for suburban and open areas

$$
K_{\text {Davidson }}=\mathrm{A}\left(h_{b}, d\right)-S_{1}(d)-S_{2}\left(h_{b}, d\right)-S_{3}(f)-S_{4}(f, d)
$$

Where

A (, and ( are distance correction factors, (, is base station antenna height correction factor, ( and (, are frequency correction factors.

A (, and ( are distance correction factors, with $\mathrm{d}$ in $\mathrm{km}$, in
- $150 \mathrm{MHz} \leq \mathrm{f} \leq 1000 \mathrm{MHz}$

- $30 \mathrm{~m} \leq \leq 200 \mathrm{~m}$

- $1 \mathrm{~m} \leq \leq 10 \mathrm{~m}$

- $1 \mathrm{~km} \leq \mathrm{d} \leq 20 \mathrm{~km}$

The following equations are used for the correction factor, introduced by Davidson:

$\mathrm{m}$;

(, is base station antenna height correction factor with $\mathrm{d}$ in $\mathrm{km}$, in $\mathrm{m}$;

( and (, are frequency correction factors with $\mathrm{f}$ in $\mathrm{MHz}$ and $\mathrm{d}$ in $\mathrm{km}$.

$$
K_{\text {Davidson }}=\mathrm{A}\left(h_{b}, d\right)-S_{1}(d)-S_{2}\left(h_{b}, d\right)-S_{3}(f)-S_{4}(f, d)
$$

Where

A $\left(h_{b}, d\right)$ and $S_{1}(d)$ are distance correction factors, $S_{2}$ $\left(h_{b}, d\right)$ is base station antenna height correction factor, $S_{3}$ $(f)$ and $S_{4}(f, d)$ are frequency correction factors. $\mathrm{A}\left(h_{b}, d\right)$ and $S_{1}(d)$ are distance correction factors, with d in $\mathrm{km}, h_{b}$ in $\mathrm{m}$;

$S_{2}\left(h_{b}, d\right)$ is base station antenna height correction factor with $\mathrm{d}$ in $\mathrm{km}, h_{b}$ in $\mathrm{m}$;

$S_{3}(f)$ and $S_{4}(f, d)$ are frequency correction factors with $\mathrm{f}$ in $\mathrm{MHz}$ and $\mathrm{d}$ in $\mathrm{km}$.

$$
\begin{gathered}
\mathrm{A}\left(h_{b}, d\right)=\left\{\begin{array}{c}
0 \\
0.62317(d-20)\left[0.5+0.15 \log \left(\frac{h_{b}}{121.92}\right)\right] \\
20<d<64.38 \mathrm{~km} \\
0.62317(d-20)\left[0.5+0.15 \log \left(\frac{h_{b}}{121.92}\right)\right] \\
20<d<300 \mathrm{~km}
\end{array}\right. \\
\mathrm{S}_{1}(\mathrm{~d})=\left\{\begin{array}{cc}
d<20 \mathrm{~km} \\
0 & \mathrm{~d}<20 \mathrm{~km} \\
0.174(\mathrm{~d}-64.38) & 20<\mathrm{d}<64.38 \mathrm{~km} \\
20<\mathrm{d}<300 \mathrm{~km}
\end{array}\right. \\
S_{2}\left(h_{b}, d\right)=0.00784\left|\log \left(\frac{9.98}{d}\right)\right|\left(h_{b}-300\right) \text { for } h_{b}<300 \\
S_{3}(f)=\frac{f}{250\left(\log \left(\frac{1500}{f}\right)\right)} \\
S_{4}(f, d)=\left[0.112\left(\log \left(\frac{1500}{f}\right)\right)\right](d-64.38) \text { for } d>64.38 \mathrm{~km}
\end{gathered}
$$

\subsection{Performance Analysis of the Models}

The statistical performance measures or goodness of fit measures for the Hata-Davidson model are defined as follows:

i) The Root Mean Square Error (RMSE) is calculated as follows:

$$
\text { MSE } \left.=\sqrt[2]{\left\{\frac{1}{n}\left[\sum_{i=1}^{i=n}\left|P L_{(\text {measured })(i)}-P L_{(\text {predicted })(i)}\right|^{2}\right]\right.}\right\}
$$

ii) Then, the Prediction Accuracy (PA, \%) based on mean absolute percentage deviation (MAPD) or Mean Absolute Percentage Error (MAPE) is calculated as follows:

$$
\mathrm{PA}=\left\{1-\frac{1}{n}\left(\sum_{i=1}^{i=n}\left|\frac{\left|P L_{(\text {measured })(i)}-P L_{(\text {predicted })(i)}\right|}{P L_{(\text {measured })(i)}}\right|\right)\right\} * 100 \%
$$

\subsection{Model Optimization Process}

The parameters of the Hata-Davidson pathloss model were adjusted (optimized) using least square algorithm to fit to measured data using the following process.

1) First, the residual (or error, e) between measured pathloss, and the Hata-Davidson model predicted pathloss is calculated for each location point, $i$.

$$
e_{(i)}=P L_{m(d B)(i)}-P r_{m(d B)(i)}
$$

2) Second, the RMSE is calculated based along with sum of errors, that is . 
3) Thirdly, if $<0$ then the optimised model is obtained by subtracting RMSE from each otherwise, if $\geq 0$ the optimised model is obtained by adding RMSE to each .

\section{Results and Discussions}

Table 1 gives the measured Received Signal Strength (RSSI), the measured pathloss and the distance of the measurement point from the GSM (Global System for Mobile communication) base station in a suburban area of Uyo, Akwa Ibom state, Nigeria. The GSM network operates in the $1800 \mathrm{MHz}$ frequency band.

Table 2 and figure 1 show the measure pathloss, the predicted pathloss by untuned Hata-Davidson model, the predicted pathloss by the RMSE-tuned Hata-Davidson model and the predicted pathloss by the multi-parameter-tuned Hata-Davidson model. The results in table 2 show that the multi-parameter-tuned Hata-Davidson model has the better prediction accuracy of $98.70720432 \%$ and RMSE of $2.177522885 \mathrm{~dB}$ as against the RMSE-tuned Hata-Davidson model with prediction accuracy of $97.42722692 \%$ and RMSE of $4.256897001 \mathrm{~dB}$. According to experts, pathloss model with RMSE of less than $6 \mathrm{~dB}$ is acceptable. In any case, the result shows that the multi-parameter tuning approach may be preferred when more accurate prediction result is required. However, the RMSE is quite simple and easier to implement even in embedded systems and systems with limited resource.

Table 1. The Measured Received Signal Strength (RSSI) and Measured Pathloss and Distance.

\begin{tabular}{llllllll}
\hline S/N & d $(\mathbf{k m})$ & RSSI (dB) & Field Measured Path Loss (dBm) & S/N & d (km) & RSSI (dB) & Field Measured Path Loss (dBm) \\
\hline 1 & 0.7726 & -79 & 132.45 & 14 & 0.900146 & -89 \\
2 & 0.8038 & -83 & 136.45 & 15 & 0.900379 & -95 & 142.45 \\
3 & 0.8199 & -83 & 136.45 & 16 & 0.91072 & -95 & 148.45 \\
4 & 0.8297 & -83 & 136.45 & 17 & 0.911539 & -95 & 148.45 \\
5 & 0.8404 & -83 & 136.45 & 18 & 0.912705 & -95 & 148.45 \\
6 & 0.8475 & -83 & 136.45 & 19 & 0.920038 & -95 & 148.45 \\
7 & 0.8568 & -89 & 142.45 & 20 & 0.921517 & -95 & 148.45 \\
8 & 0.8630 & -89 & 142.45 & 21 & 0.92993 & -95 & 148.45 \\
9 & 0.8632 & -89 & 142.45 & 22 & 0.935997 & -95 & 148.45 \\
10 & 0.8713 & -89 & 142.45 & 23 & 0.950936 & -95 & 148.45 \\
11 & 0.8784 & -89 & 142.45 & 24 & 0.96501 & -95 & 148.45 \\
12 & 0.8903 & -89 & 142.45 & 25 & 0.983726 & -95 \\
13 & 0.8936 & -89 & 142.45 & 26 & 1.001317 & -95 \\
14 & 0.9001 & -89 & 142.45 & 27 & 1.011593 & -97 \\
\hline
\end{tabular}

Table 2. Measure Pathloss, Predicted Pathloss By Untuned and Tuned Hata-Davidson Models.

\begin{tabular}{|c|c|c|c|c|c|}
\hline $\mathbf{S} / \mathbf{N}$ & d (km) & $\begin{array}{l}\text { Field Measured } \\
\text { Path Loss }(\mathrm{dBm})\end{array}$ & $\begin{array}{l}\text { Pathloss Predicted By } \\
\text { Untuned Hata-Davidson }\end{array}$ & $\begin{array}{l}\text { Pathloss Predicted By } \\
\text { RMSE-Tuned Hata-Davidson }\end{array}$ & $\begin{array}{l}\text { Pathloss Predicted By } \\
\text { Multi-parameter-Tuned Hata-Davidson }\end{array}$ \\
\hline 1 & 0.772603 & 132.45 & 194.5315667 & 141.4519063 & 133.3167896 \\
\hline 2 & 0.803794 & 136.45 & 195.1579865 & 142.0783261 & 136.196652 \\
\hline 3 & 0.819946 & 136.45 & 195.4728802 & 142.3932198 & 137.6443243 \\
\hline 4 & 0.829696 & 136.45 & 195.6599952 & 142.5803347 & 138.5045546 \\
\hline 5 & 0.840393 & 136.45 & 195.8627504 & 142.78309 & 139.4366887 \\
\hline 6 & 0.847533 & 136.45 & 195.9966457 & 142.9169853 & 140.0522505 \\
\hline 7 & 0.856774 & 142.45 & 196.1682945 & 143.088634 & 140.8413774 \\
\hline 8 & 0.862983 & 142.45 & 196.2825869 & 143.2029265 & 141.3668182 \\
\hline 9 & 0.863182 & 142.45 & 196.286228 & 143.2065675 & 141.3835574 \\
\hline 10 & 0.871291 & 142.45 & 196.4342326 & 143.3545722 & 142.0639844 \\
\hline 11 & 0.878356 & 142.45 & 196.5620523 & 143.4823919 & 142.6516147 \\
\hline 12 & 0.890336 & 142.45 & 196.776467 & 143.6968066 & 143.6373511 \\
\hline 13 & 0.893609 & 142.45 & 196.8345553 & 143.7548948 & 143.9044023 \\
\hline 14 & 0.900146 & 142.45 & 196.9499155 & 143.870255 & 144.4347519 \\
\hline 15 & 0.900379 & 148.45 & 196.954018 & 143.8743576 & 144.4536126 \\
\hline 16 & 0.91072 & 148.45 & 197.1347703 & 144.0551099 & 145.2845916 \\
\hline 17 & 0.911539 & 148.45 & 197.1489902 & 144.0693297 & 145.3499651 \\
\hline 18 & 0.912705 & 148.45 & 197.1692174 & 144.0895569 & 145.4429565 \\
\hline 19 & 0.920038 & 148.45 & 197.2958754 & 144.216215 & 146.0252462 \\
\hline 20 & 0.921517 & 148.45 & 197.3213044 & 144.241644 & 146.1421518 \\
\hline 21 & 0.92993 & 148.45 & 197.4651553 & 144.3854949 & 146.8034826 \\
\hline 22 & 0.935997 & 148.45 & 197.5680686 & 144.4884081 & 147.2766095 \\
\hline 23 & 0.950936 & 148.45 & 197.8187074 & 144.739047 & 148.4288805 \\
\hline 24 & 0.96501 & 148.45 & 198.0512414 & 144.971581 & 149.4979174 \\
\hline
\end{tabular}




\begin{tabular}{llllll}
\hline S/N & \multirow{2}{\text{d(km)}}{} & $\begin{array}{l}\text { Field Measured } \\
\text { Path Loss (dBm) }\end{array}$ & $\begin{array}{l}\text { Pathloss Predicted By } \\
\text { Untuned Hata-Davidson }\end{array}$ & $\begin{array}{l}\text { Pathloss Predicted By } \\
\text { RMSE-Tuned Hata-Davidson }\end{array}$ & $\begin{array}{l}\text { Pathloss Predicted By } \\
\text { Multi-parameter-Tuned Hata-Davidson }\end{array}$ \\
\hline 25 & 0.983726 & 148.45 & 198.3552694 & 145.275609 & 150.8956364 \\
26 & 1.001317 & 148.45 & 198.6358081 & 145.5561477 & 152.1853672 \\
27 & 1.011593 & 150.45 & 198.7974058 & 145.7177454 & 152.928286 \\
RMSE & & 53.07966043 & 4.256897001 & 2.177522885 \\
\multicolumn{2}{l}{ Prediction Accuracy (\%) } & 63.0840512 & 97.42722692 & 98.70720432 \\
\hline
\end{tabular}

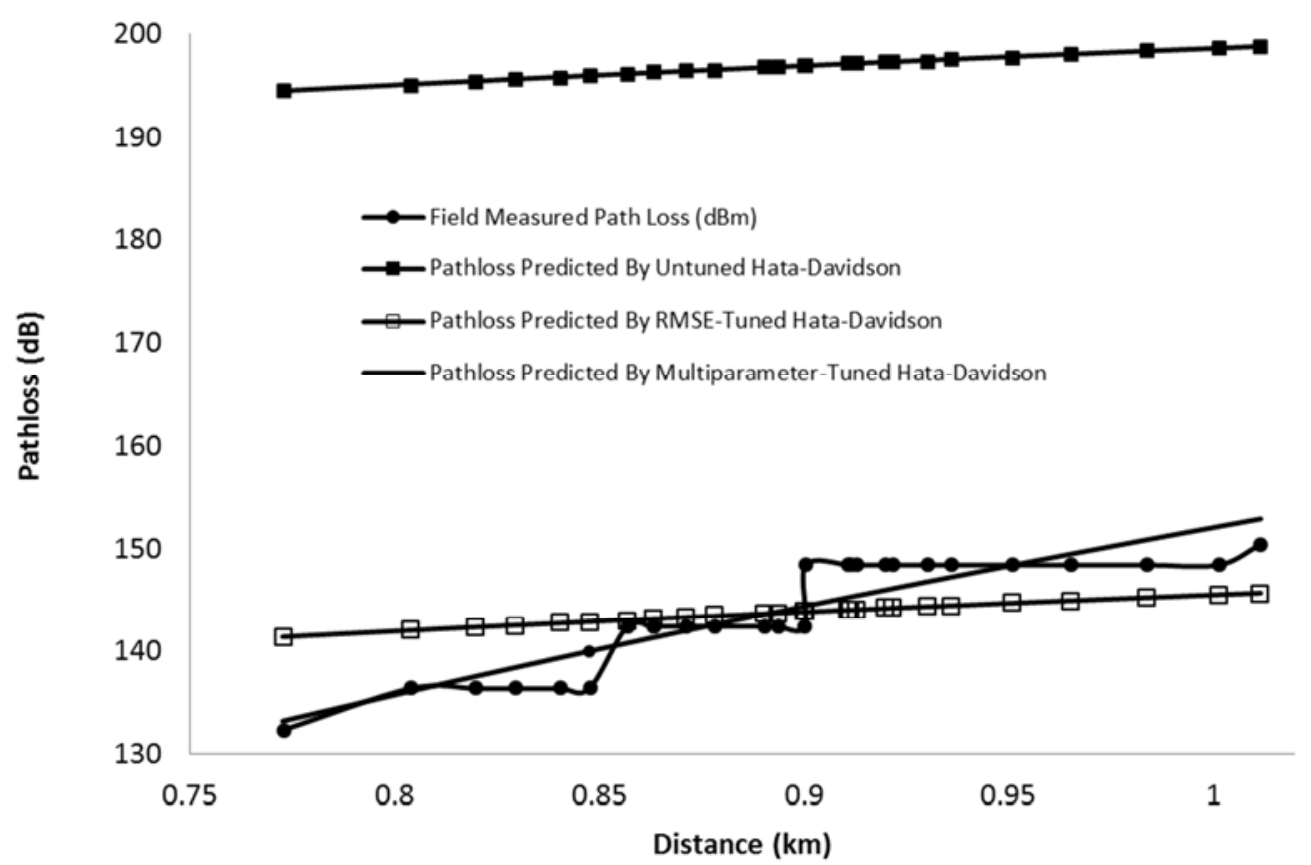

Figure 1. Measure Pathloss, Predicted Pathloss By Untuned, Pathloss Predicted By The RMSE-Tuned Hata-Davidson Model and Pathloss Predicted By The Multi-parameter-Tuned Hata-Davidson Model.

For the multi-parameter tuning, the parameters tuned are:

(i) The constant 69.55 the expression for A, hence, A for the tuned Hata-Davidson model is

$$
\begin{gathered}
A=25.33162938+26.16 * \log _{10}(f)-13.82 * \\
\log _{10}\left(h_{b}\right)-a\left(h_{m}\right)
\end{gathered}
$$

(ii) The constant 69.55 the expression for $\mathrm{B}$, hence, $\mathrm{B}$ for the tuned Hata-Davidson model is

$$
B=175.6953369-6.55 * \log _{10}\left(h_{b}\right)
$$

(iii) The constant 0.00784 the expression for $S_{2}$, hence, $S_{2}$ for the tuned Hata-Davidson model is;

$S_{2}\left(h_{b}, d\right)=0.009022299\left|\log \left(\frac{9.98}{d}\right)\right|\left(h_{b}-300\right)$ for $h_{b}<300$

\section{Conclusion}

In this paper, comparative study of RMSE-base tuning and multi-parameter-based tuning of Hata-Davidson pathloss model for a suburban area is presented. The study was based on field measurement of received signal strength for a GSM network that operates in the $1800 \mathrm{MHz}$ frequency band. The results show that the multi-parameter-based tuning performs better than the RMSE-base tuning. However, the RMSE-base tuning is simpler and easier to implement in resource limited systems.

\section{References}

[1] Liechty, L. C. (2007). Path loss measurements and model analysis of a $2.4 \mathrm{GHz}$ wireless network in an outdoor environment (Doctoral dissertation, Georgia Institute of Technology).

[2] Bola, G. S., \& Saini, G. S. (2013). Path Loss Measurement and Estimation Using Different Empirical Models For WiMax In Urban Area. International Journal of Scientific \& Engineering Research, 4 (5).

[3] Obot, A., Simeon, O., \& Afolayan, J. (2011). Comparative analysis of path loss prediction models for urban macrocellular environments. Nigerian journal of technology, 30 (3), 50-59.

[4] Ogundapo, E. O., Oborkhale, L. I., \& Ogunleye, S. B. (2011).

[5] Comparative Study of Path Loss Models for Wireless Mobile Network Planning. International Journal of Engineering and Mathematical Intelligence, 2 (1-3), 19-22.

[6] Faruk, N., Adediran, Y. A., \& Ayeni, A. A. (2013, July). error bounds of empirical path loss models at vhf/uhf bands in kwara state, Nigeria. InEUROCON, 2013 IEEE (pp. 602-607). IEEE.

[7] Faruk, N., Ayeni, A. A., \& Adediran, Y. A. (2013). Impact of Empirical Path loss models on Spatial TV white space Utilization. European scientific journal. 
[8] Faruk, N., Ayeni, A., \& Adediran, Y. A. (2013). On the study of empirical path loss models for accurate prediction of TV signal for secondary users. Progress In Electromagnetics Research B, 49, 155-176.

[9] Dalela, C., Prasad, M. V. S. N., \& Dalela, P. K. (2012). Tuning of COST-231 Hata model for radio wave propagation predictions. Computer Science and Information Technology (CS \& IT), DOI, 10, 255-267.

[10] Isabona, J., \& Azi, S. (2012). Optimized Walficsh-Bertoni Model for Pathloss Prediction in Urban Propagation Environment. International Journal of Engineering and Innovative Technology (IJEIT) Volume, 2, 14-20.

[11] Chen, Y. H., \& Hsieh, K. L. (2006, May). A dual least-square approach of tuning optimal propagation model for existing $3 \mathrm{G}$ radio network. In 2006 IEEE 63rd Vehicular Technology Conference (Vol. 6, pp. 2942-2946). IEEE.
[12] Faruk, N., Adediran, Y. A., \& Ayeni, A. A. (2013, May). Optimization of Davidson Model based on RF measurement conducted in UHF/VHF bands. In Proceedings of 6th IEEE Conference on Information Technology.

[13] Ajose, S. O., and Imoize, A. L. (2013). Propagation measurements and modelling at $1800 \mathrm{MHz}$ in Lagos Nigeria. International Journal of Wireless and Mobile Computing, 6 (2), $165-174$.

[14] Seybold, J. S. (2005) Introduction to RF Propagation, John Wiley and Sons Inc., New Jersey.

[15] Rappaport, T. S. (2002) Wireless Communication: Principles and Practice, 2nd ed., Prentice Hall, Upper Saddle River, NJ, USA. 